\title{
Understanding the seasonal and reproductive biology of olive fruit fly is critical to its management
}

\begin{abstract}
by Hannah J. Burrack, Ray Bingham, Richard Price, Joseph H. Connell, Phil A. Phillips, Lynn Wunderlich, Paul M. Vossen, Neil V. O'Connell, Louise Ferguson and Frank G. Zalom
\end{abstract}

The olive fruit fly was first detected in Los Angeles in 1998 and in all the olive-growing regions of California soon after. Following its initial detection, UC researchers and Cooperative Extension farm advisors, county agricultural commissioners and the California Department of Food and Agriculture Pest Detection and Emergency Project established a statewide monitoring program to determine the extent of the olive fruit fly's occurrence, track its seasonal biology and evaluate monitoring tools. Fly populations and infestations can reach high levels throughout California but tend to be lower in the San Joaquin Valley. Trap captures typically exhibit a bimodal distribution with peaks in the spring and fall. Olive infestation is related to fly densities, climate and fruit size. Gravid, mated females vary in density throughout the year but are present at some level year-round. The data is being used to develop models that will better predict when the adults are active and olives are at risk.

he olive fruit fly was first detected
in California in 1998 in the Los Angeles Basin and was subsequently found in all olive-growing areas within 4 years (fig. 1). The olive fruit fly (Bactrocera oleae [Rossi]) is the primary pest of olives worldwide and is particularly troublesome due to its multiple, overlapping generations each year. This life history makes understanding olive fruit fly phenology and infestation patterns

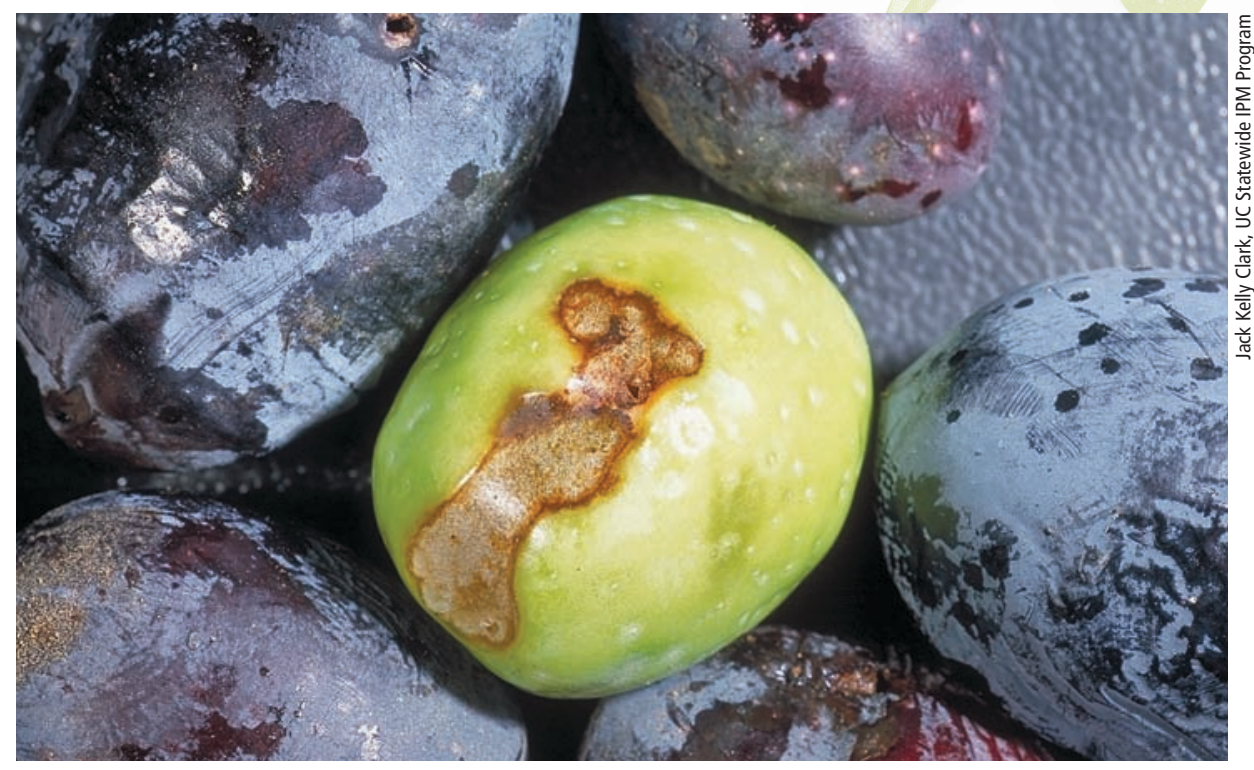

First detected in 1998, the olive fruit fly spread quickly throughout the state's olive-growing regions. The table olive industry has zero tolerance for damaged fruit, but infestation levels of $10 \%$ or more may be acceptable for olive oil. Above, the adult fly's exit holes; larvae feed just below.

particularly important for effective management.

The insect's historic range includes all of Europe and Africa, and extends at least as far east as India (Augustinos et al. 2002; Nardi et al. 2005). Molecular studies of B. oleae in California suggest that the invasion originated from Mediterranean populations. Australia is the only country where olives are grown that is not colonized. In the traditional olive-growing regions of Europe and the Middle East, the olive fruit fly is the primary economic pest. B. oleae has become the most important pest of California olives (Collier and Van Steenwyk 2003; Daane et al. 2005), and in commercial production control necessitates regular applications of insecticidal bait sprays from fruit-set through harvest.

The majority of California's crop is processed for table olives and is grown in the Sacramento and San Joaquin valleys, in Butte, Glenn, Tehama and Tulare counties (Connell 2005). Olive oil is also produced from California olives. At the onset of the olive fruit fly invasion, oil production occurred primarily in coastal counties, including Napa and Sonoma. In recent years, oil production has been increasing in the traditional table olive-producing counties. B. oleae is managed differently in these two production systems: there is zero tolerance for infestation in table olives, while a threshold of roughly $10 \%$ infestation is acceptable for oil olives, although even greater levels can produce high-quality oil if the fruit is processed quickly (Kicenik Devarenne and Vossen 2007).

This production difference is particularly notable in Butte County, where high fly densities and associated damage resulted in crop rejection by table olive processors. Consequently, olives grown in Butte County are crushed for oil. Super-high-density oil plantings have been established in Butte County since 1999. These plantings - in which olive trees are spaced more closely, varieties with smaller fruit are planted and deficit irrigation is used - appear to be less conducive to olive fruit fly infestation (Vossen 2007) (see page 34).

\section{Statewide monitoring program}

We and other researchers were interested in understanding the seasonal activity patterns of B. oleae in California as compared to its previously known range, in order to predict where and when the fly was most likely to become a significant pest. In 2002, UC 
researchers and Cooperative Extension farm advisors, California Department of Food and Agriculture Pest Detection and Emergency Project personnel, county agricultural commissioners and pest control advisers assembled a network of monitoring sites throughout the state, in order to determine olive fruit fly population dynamics within and between California's diverse climatic and geographic regions. A network of 28 monitoring sites in 16 counties was established and data was collected from 2002 through 2006 (table 1).

This large dataset allowed us to track B. oleae activity patterns and to relate these patterns to fly and fruit biology. The end-product of this work will be predictive models for fly activity and fruit infestation. Because the initial goal of this monitoring effort was to track $B$. oleae seasonal biology, sites with active, relatively large populations were selected, and all traps were placed in olive plantings that received no insecticide applications for the duration of the study. Therefore, all population fluctuations observed were due to local biotic and abiotic factors, not anthropogenic effects.

The selection of untreated sites with large B. oleae populations led to a lack of locations in the San Joaquin Valley, because most olive plantings in this area are used for commercial table olive production and may be treated with pesticides if B. oleae are present. In addition, other researchers documented that populations in the San Joaquin Valley appear naturally lower than coastal and Sacramento Valley locations (Rice et al. 2003; Yokoyama et al. 2006). The olive fruit fly had already been detected in 35 counties prior to 2002. After the monitoring program was initiated, it was found in nine more counties (fig. 1), although the detection years do not necessarily indicate initial invasion. This is particularly clear in the case of Colusa County, which was surrounded by counties in which the fly had been detected, but for which there were no records of olive fruit fly until 2004.

\section{Geography and seasonal activity}

Statewide monitoring began using four ChamP yellow sticky traps per site baited with ammonium bicarbonate food lures attractive to both sexes and a spiroketal pheromone lure attractive to males (Yokoyama et al. 2006). Plastic McPhail traps (Liquibaitor trap, Great Lakes IPM, Vestaburg, Mich.) baited with an aqueous torula yeast food lure attractive to both sexes were shown to be more attractive than ChamP traps (Burrack et al. 2008), and in 2003 all monitoring locations began to use two to four of the McPhail traps.

Every week the traps were checked, flies were counted and sexed, and lures were changed. Trapping was conducted from April through December at most locations, with a subset of locations (Butte 1, Napa 1, Napa 2, Napa 3, Napa 4, San Diego 1, San Luis Obispo 2, Solano 4, and Yolo 1) continuing year-round. Weekly trap

\begin{tabular}{|c|c|c|c|c|}
\hline County & Site & No. of traps & Geographic area & Years active \\
\hline Amador & 1 & 4 & North, inland & 2005 \\
\hline Butte & 1 & 4 & North, inland & 2002, 2003, 2004, 2005 \\
\hline Calaveras & 1 & 2 & North, inland & 2002, 2003, 2004, 2005 \\
\hline Marin & 1 & 2 & North, coastal & 2002, 2003, 2004 \\
\hline \multirow[t]{4}{*}{ Napa } & 1 & 2 & North, coastal & 2002, 2003, 2004, 2005, 2006 \\
\hline & 2 & 2 & North, coastal & 2002, 2003, 2004, 2006 \\
\hline & 3 & 2 & North, coastal & 2002, 2003, 2004, 2006 \\
\hline & 4 & 2 & North, coastal & 2002, 2003, 2004, 2006 \\
\hline \multirow[t]{4}{*}{ Sacramento } & 1 & 2 & North, inland & $2002,2003,2004$ \\
\hline & 2 & 2 & North, inland & 2005 \\
\hline & 3 & 2 & North, inland & 2004 \\
\hline & 4 & 2 & North, inland & 2004 \\
\hline San Diego & 1 & 2 & South, coastal & 2002, 2003, 2004, 2005 \\
\hline \multirow[t]{2}{*}{ San Luis Obispo } & 1 & 2 & South, coastal & 2002, 2003, 2004, 2005, 2006 \\
\hline & 2 & 2 & South, coastal & 2002, 2003, 2004, 2005, 2006 \\
\hline \multirow[t]{2}{*}{ Santa Barbara } & 1 & 2 & South, coastal & 2004 \\
\hline & 2 & 2 & South, coastal & 2004 \\
\hline Shasta & 1 & 2 & North, inland & 2002, 2003, 2004, 2005 \\
\hline \multirow[t]{4}{*}{ Solano } & 1 & 2 & North, inland & 2002, 2003, 2004 \\
\hline & 2 & 2 & North, inland & 2002, 2003, 2004, 2005, 2006 \\
\hline & 3 & 2 & North, inland & 2002, 2003, 2004 \\
\hline & 4 & 4 & North, inland & 2002, 2003, 2004, 2005, 2006 \\
\hline \multirow[t]{2}{*}{ Sonoma } & 1 & 2 & North, coastal & $2002,2003,2004,2005$ \\
\hline & 2 & 2 & North, coastal & $2003,2004,2005,2006$ \\
\hline Tulare & 1 & 4 & South, inland & 2005 \\
\hline Ventura & 1 & 4 & South, coastal & 2005 \\
\hline Yolo & 1 & 4 & North, inland & 2002, 2003, 2004, 2005, 2006 \\
\hline Yuba & 1 & 2 & North, inland & 2003,2004 \\
\hline
\end{tabular}

Fig. 1. Years of initial olive fruit fly detection in California counties. 

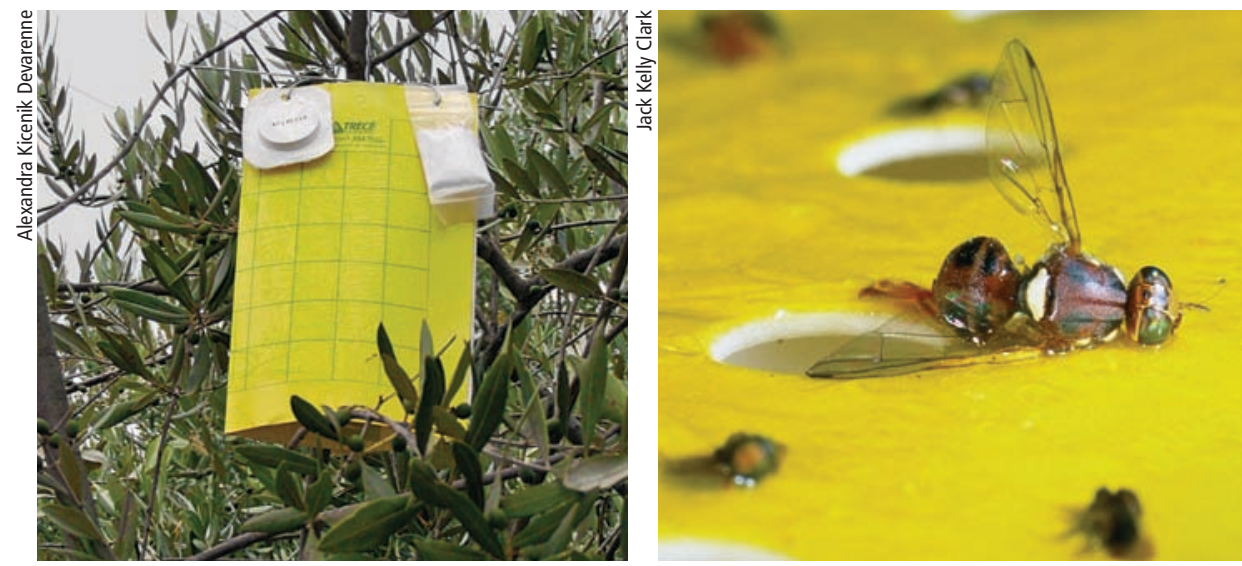

Yellow sticky traps, left, are used to monitor the fly's population densities in different locations throughout the year. Right, an adult olive fruit fly caught in a trap.

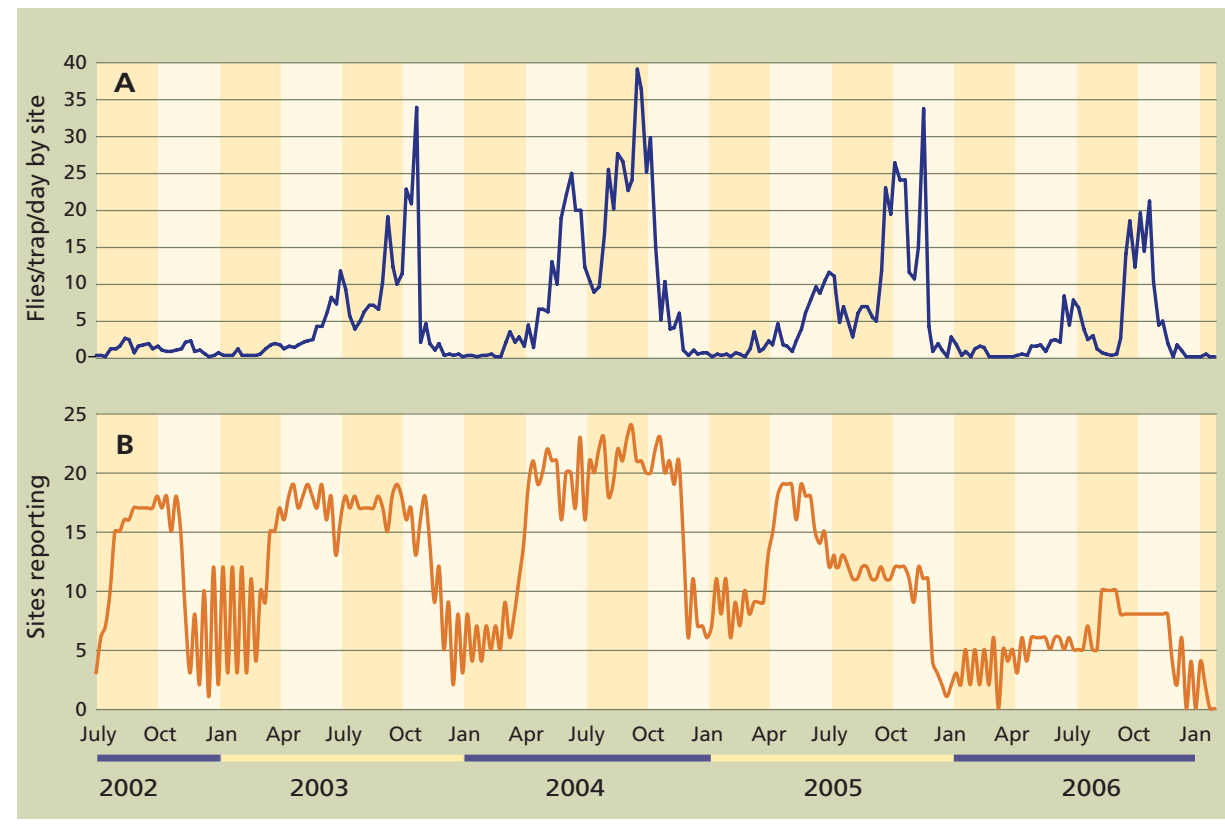

Fig. 2. (A) Average flies per trap per day caught at all monitoring locations over 4 years and (B) number of trapping locations reporting each week.

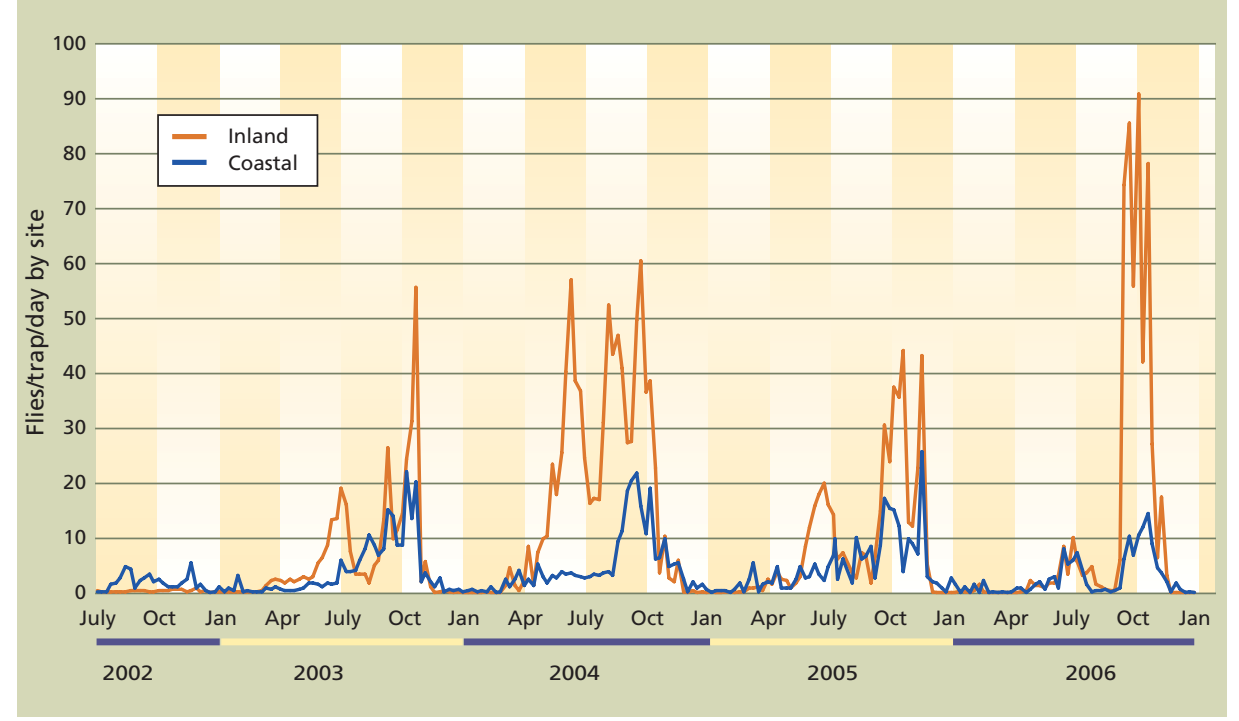

Fig. 3. Flies per trap per day caught at combined inland and coastal trapping locations over 4 years. captures were converted to flies per trap per day to allow for comparison between locations. Flies per trap per day were summed, divided by the number of locations reporting data for the week, and graphed to allow observation and comparison of population density trends.

Olive fruit fly flight activity has a bimodal distribution, with the highest trap captures observed in spring and fall (fig. 2A). Depending on location, spring peaks occur in March, April or May and fall peaks are in September, October or November. The majority of the pooled trapping data points represented at least 15 monitoring sites (fig. 2B), except for the winter dates. Overall fly activity was low in the winter, and the locations selected for winter monitoring were among those with the highest B. oleae trap captures during the previous summer and fall. Flies were still present during winter at these locations, but were trapped in lower numbers. Trap captures were lower in 2002 than in subsequent years, likely due to the use of a less efficient trap and the shorter time since initial B. oleae establishment in more northern locations.

When sites were grouped into broad geographic categories, differences in seasonal activity became apparent. We considered a trapping site to be coastal if it was either in a county directly bordering the ocean or west of the summit of the coastal mountain range. Coastal locations have milder climates than those inland, with cooler summers and warmer winters. We considered trapping locations to be northern when they were situated at greater than $37^{\circ}$ N latitude (roughly Santa Cruz), with the remainder categorized as southern. Both coastal and inland locations included sites with very high $(10,000$ or more flies; San Diego, Butte and Solano 2) and very low (under 1,000 flies; Marin and Tulare) trap captures (table 2). Trap data from the same geographic areas was pooled and graphed.

The sites from Northern and Southern California displayed similar activity patterns and are not presented, but fly trap capture patterns at inland versus coastal locations differed markedly (fig. 3). The pooled inland locations exhibited similar bimodal trap capture patterns to those observed for 
combined data from all sites (fig. 2A), but pooled coastal locations lacked a spring peak and displayed a gradual increase of fly captures, with the greatest numbers captured in the fall (fig. 3).

\section{Tracking olive infestations}

Olive infestation and olive size were tracked in 2004 and 2005 at seven locations, and fly density was tracked during 2005. Manzanillo and Mission olives, the most commonly grown varieties in California (Connell 2005), were sampled at most locations, and Leccino olives were sampled at one location because no suitable Manzanillo or Mission olives were available (table 3). One hundred olives were collected weekly from four trees at each location, June through December 2004, and May through December 2005. Sample size was decreased to 52 olives per tree when fruit infestation reached $50 \%$.

Olives were dissected under a stereomicroscope, and oviposition scars (stings), live larvae, and pupae or larval/adult exit holes were counted. Olives bearing stings were considered infested, as table olive producers have a zero tolerance policy for olive fruit fly infestation. Prior to dissection, each olive was measured to compare fruit size across locations, because olive fruit fly adults exhibit a preference for large fruit under field conditions (Burrack and Zalom 2008; Yokoyama et al. 2006). The longest point on the olive $(l)$, the widest point $(w)$ and $90^{\circ}$ from the widest dimension $(h)$ were measured and used to calculate fruit volume $(V=$ $(4 / 3 \pi)(h / 2)(w / 2)(l / 2))$. Fly populations were monitored at each location using four plastic McPhail traps, as described previously. Data from 2004 and 2005 was similar for all locations, therefore data from 2005 is presented.

Infestation levels in 2005 reached $100 \%$ in Butte and Ventura counties. Infestations grew slowly at the Amador and Sonoma sites but were high by the end of the season (fig. 4A). Fly trap captures mirrored the delayed infestation pattern at Amador and Sonoma (fig. 4B), and these two locations had the smallest olives throughout the season (fig. 4C). Smaller olives are typically less infested in the field (Burrack and Zalom 2008), and both fly population and olive size are affected by weather. Infestation levels and trap captures were low in Tulare County for the entire season, despite olive size and development comparable to the other monitoring locations (figs. 4A, 4B and 4C).

Previous monitoring efforts have also reported lower trap captures in
San Joaquin Valley locations (Rice et al. 2003; Yokoyama et al. 2006). B. oleae populations in the Central Valley may be limited by high temperature and food resources (Wang et al. 2009) (see page 29). Solano County Mission olives were significantly less infested than

\begin{tabular}{|c|c|c|c|c|c|}
\hline \multirow[t]{2}{*}{ County } & \multirow[t]{2}{*}{ Site } & \multirow[t]{2}{*}{ No. of traps } & \multirow[t]{2}{*}{2003} & 2004 & 2005 \\
\hline & & & & mber of & $\ldots \ldots$ \\
\hline Amador & 1 & 4 & $-\dagger$ & - & 10,718 \\
\hline Butte & 1 & 4 & 3,880 & 10,956 & 8,487 \\
\hline Calaveras & 1 & 2 & 406 & 4,692 & - \\
\hline Marin & 1 & 2 & 331 & 78 & - \\
\hline \multirow{4}{*}{ Napa } & 1 & 2 & 3,499 & 2,039 & 1,369 \\
\hline & 2 & 2 & 1,459 & 2,459 & - \\
\hline & 3 & 2 & 1,920 & 3,034 & - \\
\hline & 4 & 2 & 1,001 & 3,397 & - \\
\hline \multirow[t]{3}{*}{ Sacramento } & 1 & 2 & - & 6,988 & - \\
\hline & 2 & 2 & - & - & 2,942 \\
\hline & 3 & 2 & - & 6,838 & - \\
\hline San Diego & 1 & 2 & 8,711 & 5,290 & 10,008 \\
\hline \multirow{2}{*}{ San Luis Obispo } & 1 & 2 & - & 1,227 & 1,191 \\
\hline & 2 & 2 & 3,765 & 3,756 & 2,339 \\
\hline \multirow[t]{2}{*}{ Santa Barbara } & 1 & 2 & - & 3,924 & - \\
\hline & 2 & 2 & - & 3,979 & - \\
\hline Shasta & 1 & 2 & 52 & 204 & 1,700 \\
\hline \multirow[t]{2}{*}{ Sonoma } & 1 & 2 & 1,857 & 4,895 & 3,058 \\
\hline & 2 & 2 & 602 & 1,207 & 1,288 \\
\hline \multirow[t]{4}{*}{ Solano } & 1 & 2 & 8,216 & 11,667 & - \\
\hline & 2 & 2 & 10,466 & 40,422 & 16,686 \\
\hline & 3 & 2 & 4,051 & 9,490 & - \\
\hline & 4 & 4 & 1,167 & 9,914 & 2,889 \\
\hline Tulare & 1 & 4 & - & - & 287 \\
\hline Ventura & 1 & 4 & - & - & 13,800 \\
\hline Yolo & 1 & 4 & 2,454 & 7,521 & 5,269 \\
\hline Yuba & 1 & 2 & 1,163 & - & - \\
\hline
\end{tabular}

TABLE 3. Olive infestation data locations

\begin{tabular}{llll}
\hline \hline County & Location & Trapping location & Varieties sampled \\
\hline Amador & Abandoned orchard & Amador 1 & Leccino \\
Butte & Commercial and fallow orchard & Butte 1 & Manzanillo, Mission \\
Sonoma & Abandoned orchard & Sonoma 2 & Mission \\
Solano & Wolfskill Experimental Orchard & Solano 4 & Manzanillo, Mission \\
Tulare & Lincove Research Station & Tulare 1 & Manzanillo \\
Ventura & Abandoned orchard & Ventura 1 & Mission \\
Yolo & UC Davis campus farm & Yolo 1 & Manzanillo, Mission \\
\hline
\end{tabular}


Manzanillo olives from the same location. Field observations from this site suggest that Manzanillo olives may be preferable to Mission for oviposition in the field when female flies have a choice (Burrack and Zalom 2008).

\section{Reproductive biology}

Examination of trap captures compared to ovarian development in the female indicated that the olive fruit fly has at least four generations per year in California, with a partial generation spanning the winter (Burrack 2007). An absence of mature eggs in fly ovaries during the spring and early summer has often been noted in European B. oleae populations (Delrio and Prota 1976; Economopoulos et al. 1982;

Fletcher et al. 1978; Raspi et al. 2002; Tzanakakis 1986) and is referred to as a summer reproductive diapause. A similar absence of mature eggs can be induced in flies reared in the laboratory by exposing larvae to cool, short days and adults to hot, long days with no

\section{(A) Fruit infested}

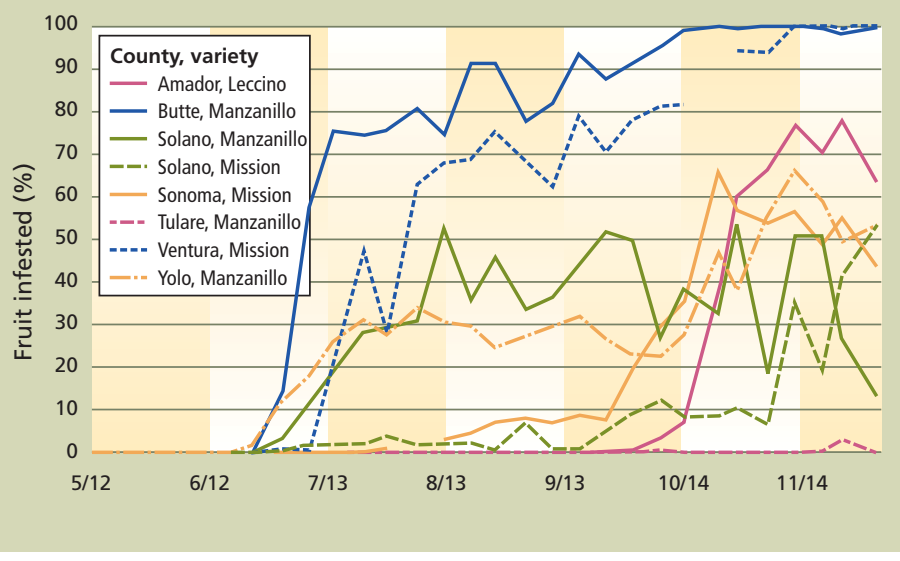

\section{(B) Flies per day}

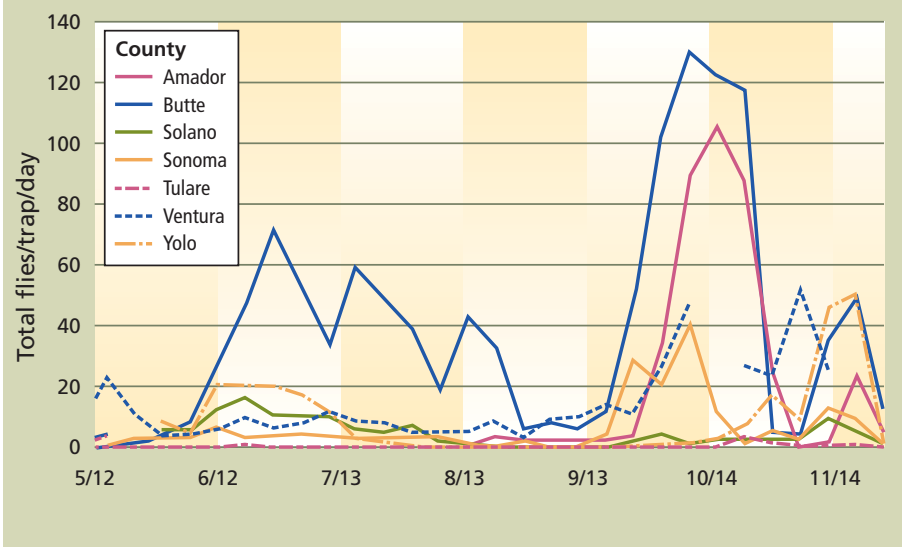

access to olives (Koveos and Tzanakakis 1990, 1993; Koveos et al. 1997; Raspi et al. 2002; Raspi et al. 2005).

In order to determine if this phenomenon occurs in California B. oleae populations as well as to determine when flies were capable of infesting olives, females flies collected from monitoring traps were dissected for five sites (Butte 1, Napa 1, San Diego 1, Solano 4 and Yolo 1). These locations were selected because trapping was conducted yearround, and they represented different California climates. Ten flies from each location and sampling date were dissected, and when fewer than 10 flies per week were collected, all flies were dissected. Ovarian development, egg load and mating status were observed for each of the dissected flies.

We determined whether the ovaries of female flies contained mature eggs and whether their spermathecae contained sperm. Mature eggs are easily distinguished from developing eggs by a distinctly darker micropile on the anterior end. Egg load, or the total number of mature eggs present in both

Fig. 4. (A) Percentage of fruit infested, sampled weekly, (B) flies caught per trap per day and (C) olive development at fruit infestation locations in 2005. Gaps in lines signify dates for which olive data was not collected. ovaries, was also determined. Mating status was determined via staining with 4', 6-diamidino-2-phenylidole dihydrocholride (DAPI) at 1 microgram per milliliter in phosphate buffered solution and observed with UV-flourescent microscopy as adapted from Fritz and Turner (2002). Flies were dissected in $70 \%$ ethyl alcohol, and spermathecae were removed, placed in a drop of DAPI on a microscope slide and crushed with a cover slip.

The morphology of the olive fruit fly spermatheca and ethanol preservation made quantification of sperm difficult. Therefore, flies were classified as mated or unmated. An overall classification of reproductive biology was assigned to each fly by combining ovarian development rankings and mating status. These categories were: (1) unmated (sperm absent), immature (immature ovaries); (2) unmated, mature (mature ovaries); (3) mated (sperm present; mature eggs in ovaries [gravid]), immature; and (4) mated, mature. Only flies in category 4 would be capable of infesting olives.

All statistical analyses were conducted using SAS version 9.1 (SAS Institute, Cary, N.C.). Analysis of variance was conducted with Proc GLM, and means were separated via LSD. Nonparametric rank tests were conducted using the Kruskal-Wallis test via Proc Nparlway in SAS.

There were significant differences between months in the proportion of unmated flies with immature ovaries and mated flies with mature ovaries observed (unmated/immature: $\mathrm{F}_{8,20}=$ 5.16, $P=0.0014$; mated $/$ mature: $\mathrm{F}_{8,20}=$ 4.94, $P=0.0018)$, but there was also a significant site/month interaction for

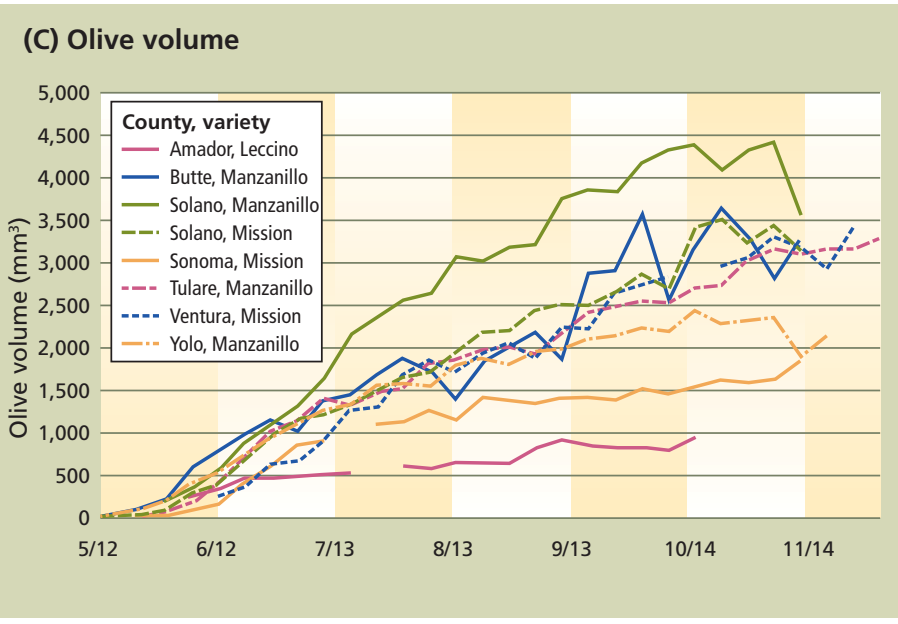


both categories (unmated/immature: $\mathrm{F}_{32,20}=4.01, P=0.0009$; mated/mature: $\left.F_{32,20}=5.17, P=0.0001\right)$. The differences among years for both rankings were nonsignificant (unmated/immature: $\mathrm{F}_{2,20}=2.36, P=0.1205$; mated/mature: $\left.\mathrm{F}_{2,20}=1.18, P=0.3267\right)$, and therefore, yearly data was pooled by month.

Because of the significant interaction effect between site and month, the data for individual sites is presented. The greatest proportion of mated, mature flies was observed in March or April and October through November, for the Yolo, Solano and Butte county sites (figs. 5A, 5B and 5C). High proportions of potentially destructive flies (mated, mature) were observed in April, August and September in Napa County (fig. 5D). The greatest proportion of unmated, reproductively immature flies throughout the year was observed at San Diego, where the highest percentage of mated, gravid flies was present in June, July and August (fig. 5E).

The proportion of reproductively immature flies increased in spring or early summer at all locations, a period during which the European literature suggests that a reproductive diapause may occur. However, reproductively mature flies were also present at this time. A decrease in mean egg load was observed during the spring and fall (data not shown). At no point during the summer months were reproductively mature females completely absent.

Egg load was positively related to mating status $\left(\mathrm{F}_{1,3049}=160.20, P<\right.$ $0.0001)$ at all locations for all months. Mean egg load was larger in mated than unmated flies, regardless of month, and was greatest in March and May and least in September. On average, mated flies had 7.30 eggs in their ovaries, while unmated flies had 2.44 eggs present. Flies with mature eggs in their ovaries were more likely to be mated $\left(\chi^{2}=1228.4922\right.$, df $\left.=1, P<0.0001\right)$.

Population densities as indicated by trap captures were high at both the Butte and San Diego sites (table 2) relative to the other sites. McPhail traps are thought to overestimate the proportion of gravid female flies in a population (Neuenschwander and Michelakis 1979), so the abundance of reproductively immature flies is likely not due to greater trap capture and it is possible that the proportion of immature flies may be even greater than that observed through trap captures. The climate at San Diego is characterized by moderate, coastal-influenced temperatures throughout the year, as opposed to hot summer and relatively cool winter temperatures that fall below

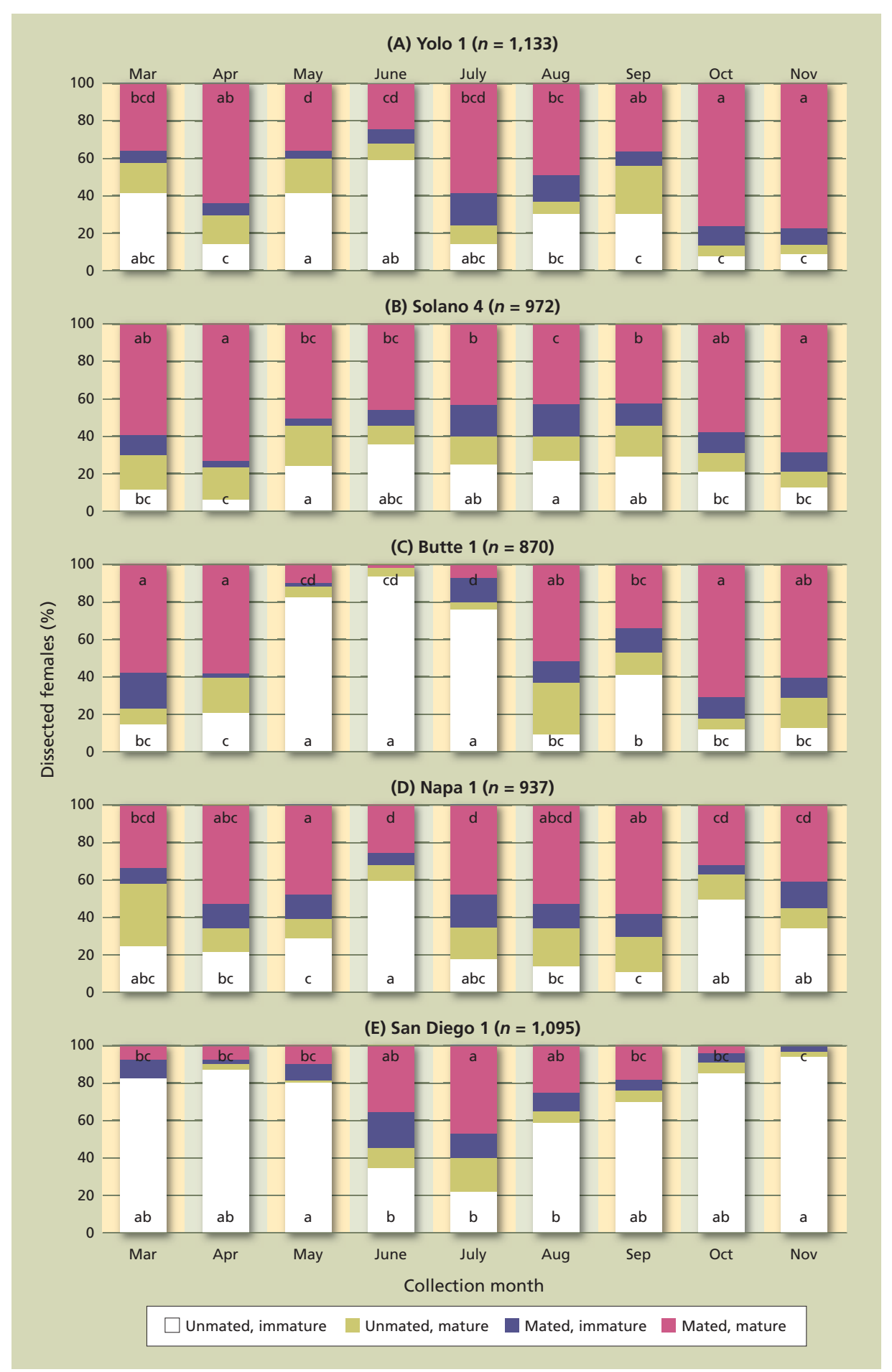

Fig. 5. Ovarian development and mating status for olive fruit fly at five locations. Flies were categorized as (1) unmated (sperm absent), immature ovaries, (2) unmated, mature ovaries, (3) mated (sperm present), immature ovaries and (4) mature, mature ovaries. Only flies in category (4) would be capable of infesting olives. Flies were collected weekly, and data pooled by month. Percentages of a given class (unmated/immature or mated/mature) indicated by the same letter for a single location were not significantly different $(\alpha=0.05)$ when adjusted means were compared via LSD; data from December, January and February was eliminated from analysis for all years due to insufficient sample sizes. 
the fruit fly development thresholds. Therefore, more-extensive generational overlap might be expected at the San Diego site than at the Butte site, resulting in more young, reproductively immature females present in the population year-round.

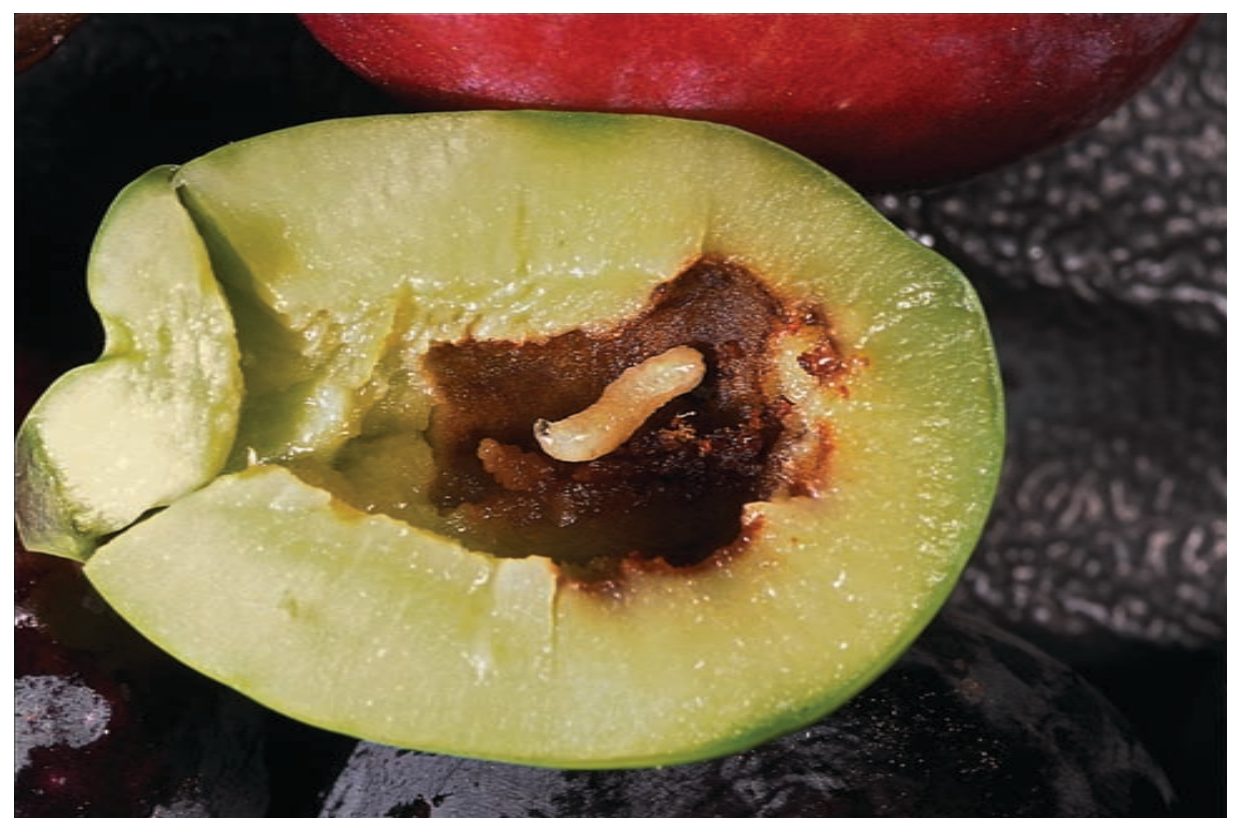

Statewide surveys have gathered important information about the life cycle of the olive fruit fly, which will be used to improve pest management practices. Above, larvae infest olive fruit.

\section{References}

Augustinos AA, Stratikopoulos EE, Zacharopoulou A, Mathiopoulos KD. 2002. Polymorphic microsatellite markers in the olive fly, Bactrocera oleae. Mol Ecol Notes 2:278-80.

Burrack HJ. 2007. The Seasonal Biology of the Olive Fruit Fly in California. Ph.D. dissertation, UC Davis. $123 \mathrm{p}$.

Burrack HJ, Connell JH, Zalom FG. 2008. Comparison of olive fruit fly (Bactrocera oleae [Rossi]) (Diptera: Tephritidae) captures in several commercial traps in California. Int J Pest Manag 54(3):227-34.

Burrack HJ, Zalom FG. 2008. Oviposition preference and larval performance of the olive fruit fly (Diptera: Tephritidae) in several commercially important olive varieties in California. J Econ Entomol 101(3):750-8. Collier TR, Van Steenwyk RA. 2003. Prospects for integrated control of olive fruit fly are promising in California. Cal Ag 57:28-31.

Connell JH. 2005. History and scope of the olive industry. In: Sibbett GS, Ferguson L (eds.). Olive Production Manual (2nd ed.). UC ANR Pub 3353. Oakland, CA. p 1-10.

Daane KM, Rice RE, Zalom FG, et al. 2005. Arthropod pests of olive. In: Sibbett GS, Ferguson L (eds.). Olive Production Manual (2nd ed.). UC ANR Pub 3353. Oakland, CA. p 105-14.

Delrio G, Prota R. 1976. Osservaziono eco-etologiche sul Dacus oleae Rossi nella Sardegna nord-occidentale. Boll Zool Agrar Bachi 2:49-118.

\section{Managing olive fruit fly}

UC researchers have developed a greater understanding of the behavior and biology of the olive fruit fly in the 12 years since its initial detection, but there is still a great deal of work to be done to develop tools to apply this information in effectively managing this pest. Models determining when olives become susceptible to olive fruit fly attack and how fly populations respond to climatic conditions are being developed using the data described here. With a few exceptions, the olive fruit fly has not prevented commercial olive production in California for most growers, but it has significantly changed their insect management requirements.

H.J. Burrack is Assistant Professor of Entomology North Carolina State University, Raleigh; R. Bingham is Entomologist, Plant Industry, California Department of Food and Agriculture; R. Price is Agricultural Commissioner, Butte County; J.H. Connell is Farm Advisor, UC Cooperative Extension (UCCE) Butte County; P.A. Phillips is Regional IPM Farm Advisor, retired; L. Wunderlich is Farm Advisor, UCCE Amador and El Dorado counties; P.M. Vossen is Farm Advisor, UCCE Sonoma and Marin counties; N.V. O'Connell is Farm Advisor, UCCE Tulare County; L. Ferguson is Professor of Plant Sciences, UC Davis; and F.G. Zalom is Professor of Entomology, UC Davis.

The authors would like to thank 19 trappers for collecting data from 28 locations in 16 counties over the course of 4 years.
Economopoulos AP, Haniotakis GE, Michelakis S, et al. 1982. Population studies on the olive fruit fly, Dacus oleae (Gmel.) (Dipt., Tephritidae) in Western Crete. Z Entomol 93:463-76.

Fletcher BS, Pappas S, Kapatos E. 1978. Changes in the ovaries of olive flies (Dacus oleae [Gmelin]) during the summer, and their relationship to temperature, humidity and fruit availability. Ecol Entomol 3:99-107.

Fritz AH, Turner FR. 2002. A light and electron microscopical study of the spermathecae and ventral receptacle of Anastrepha suspensa (Diptera: Tephritidae) and implications in female influence of sperm storage. Arth Struc Dev 30:293-313.

Kicenik Devarenne A, Vossen PM. 2007. Monitoring and organic control of olive fruit fly. In: Vossen PM

(ed.). Organic Olive Production Manual. UC ANR Pub 3505. Oakland, CA. p 47-51.

Koveos DS, Broufas GD, Kiliaraki EK, Tzanakakis ME. 1997. Effect of prevention of flight on ovarian maturation and reproductive diapause in the olive fruit fly (Diptera: Tephritidae). Ann Entomol Soc Am 90:337-40.

Koveos DS, Tzanakakis ME. 1990. Effect of the presence of olive fruit on ovarian maturation in the olive fruit fly, Dacus oleae, under laboratory conditions. Entomol Exp Appl 55:161-8.

Koveos DS, Tzanakakis ME. 1993. Diapause aversion in the adult olive fruit fly through effects of the host fruit, bacteria and adult diet. Ann Entomol Soc Am 86:668-73.

Nardi F, Carapelli A, Dallai R, Roderick GK. 2005. Population structure and colonization history of the olive fly, Bactrocera oleae (Diptera, Tephritidae). Mol Ecol 14:2729-38
Neuenschwander P, Michelakis S. 1979. McPhail trap captures of Dacus oleae (Gmel.) (Diptera, Tephritidae) in comparison to the fly density and population composition as assessed by sondage in Crete, Greece. Mitt Schweiz Entomol Ges 52:343-57.

Raspi A, Canale A, Loni A. 2005. Presence of mature eggs in olive fruit fly, Bactrocera oleae (Diptera Tephritidae), at different constant photoperiods and at two temperatures. Bull Insectol 58:125-9.

Raspi A, lacono E, Canale A. 2002. Variable photoperiod and presence of mature eggs in olive fruit fly, Bactrocera oleae (Rossi) (Diptera Tephritidae). Redia 85:111-9.

Rice RE, Phillips PA, Stewart-Leslie J, Sibbett GS. 2003. Olive fruit fly populations measured in Central and Southern California. Cal Ag 57(4):122-7.

Tzanakakis ME. 1986. Summer diapause in the olive fruit fly and its significance. Int Symp Fruit Flies of Economic Importance, Crete. p 383-6.

Vossen PM. 2007. Olive oil: History, production and characteristics of the world's classic oils. HortScience 42(5):1093-100.

Wang X-G, Johnson MW, Daane KM, Nadel H. 2009. High summer temperatures affect the survival and reproduction of olive fruit fly (Diptera: Tephritidae). Env Entomol 38(5):1496-504.

Yokoyama VY, Miller GT, Stewart-Leslie J, et al. 2006. Olive fruit fly (Diptera: Tephritidae) populations in relation to region, trap type, season and availability of fruit. J Econ Entomol 99(6):2072-9. 